\title{
Challenges of Hybrid Electric Vehicle for Military Application
}

\author{
Prashant Gocher ${ }^{1}$, Pradeep Kumar' ${ }^{1}$, Gaurav Srivastava ${ }^{2}$ \\ ${ }^{1}$ B.Tech Scholar, ${ }^{2}$ Assistant Professor \\ ${ }^{1,2}$ Poornima College of Engineering, Jaipur, Rajasthan, India
}

\begin{abstract}
How to cite this paper: Prashant Gocher | Pradeep Kumar | Gaurav srivastava"Challenges of Hybrid Electric Vehicle for Military Application" Published in International Journal of Trend in Scientific Research and Development (ijtsrd), ISSN: 24566470, Volume-3 | Issue-3, April 2019, pp.226-227, URL: http://www.ijtsrd.co $\mathrm{m} /$ papers/ijtsrd216 99.pdf

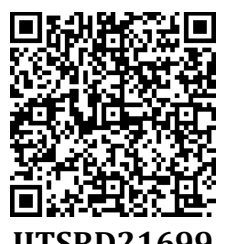

Copyright (C) 2019 by author(s) and International Journal of Trend in Scientific Research and Development Journal. This is an Open Access article distributed under the terms of the Creative Commons

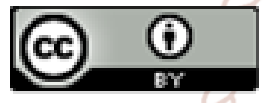
Attribution License (CC BY 4.0) (http://creativecommons.org/licenses/ by/4.0)

\section{INTRODUCTION}

A half and half electric vehicle (HEV) is a kind of cross breed vehicle that joins an ordinary inner ignition motor (ICE) framework with an electric impetus framework (crossover vehicle drive train). One of the important HEV is the half and half electric vehicle, albeit mixture electric trucks (pickups and tractors) and transports additionally exist. Current HEVs make utilization of proficiency improving advances, for example, regenerative brakes which convert the vehicle's active vitality to electric vitality, which is put away in a battery or super capacitor. Numerous HEVs decrease inactive emanations by closing down the motor out of gear and restarting it when required; this is known as a begin stop framework.

\section{POTENTIAL PAYOFF'S}

The adjustments of a half breed electric drive incorporate fuel economy, adaptability, quiet activities, and lower warm signature, what's more, locally available and send out electric power. The accompanying sections are short portrayals of every one of these adjustments.

\section{A. Fuel Efficiency}

All types of electrical modules enable the motor to work on their better effective modes at the different speeds because of the truth that the motor speed isn't connected to the earth speed. In the instance of a mixture electric design, the efficiency advantage can be boosted with vitality stockpiling framework.,. For this situation, control is drawn from the battery amid transient conditions, beginning where the motor regularly utilizes the greatest measure of fuel. A cross breed vehicle regularly begins moving with the motor off and proceeds on the battery control until extra power is required from the motor. As the vehicle backs off the footing engine can turn into a determined generator through appropriate controls furthermore, the majority of the brake vitality for this situation is recouped and reestablished in the battery.

\section{B. Noiseless Work}

Quiet watch is a necessity the Army has been attempting to characterize for quite a while regarding burdens and lengths. Quiet watch missions are led with the motor off. Amid quiet activities, the heaps shift starting with one vehicle mission then onto the next from couple of kilowatts to several kilowatts. Furthermore, the length of the quiet tasks can likewise fluctuate with different missions.

\section{Locally Available Power}

One of the most important benefit of cross-breed innovation used for defense purposes is their capability to produce electricity by themselves with the help of some motorgenerator sets and use this generated power for driving the vehicle and other equipments used in the vehicle, because of this advantage we can use the cross-breed fighter vehicles 
continuously for larger duration of time during war between countries.

\section{Challenges}

The difficulties confronting half breed electric innovation are: a specialized angle and a cost perspective. The specialized angle is for the most part connected with the combination of segments that-moving forward without any more development are excessively extensive and unreasonably substantial for the ground battle vehicles. In expansion, most segments especially the power electronics based power hardware work at generally less temperature subsequently, the cooling framework required to keep the parts from achieving their warm points of confinement is excessively substantial and its capacity draw from the prime mover is extreme which moreover drives the motor size. The warm administration challenge isn't one of a kind to the control hardware; the battery pack likewise displays a warm issue at temperature boundaries particularly at temperatures above $60 \mathrm{C}$ and beneath short - $40 \mathrm{C}$.

The second part of the difficulties is the expense. Cross breed vehicle innovations for both military and business applications are still being developed despite the fact that business half and half electric autos, trucks and transports are in constrained generation. The as of now accessible cross breed electric parts are appropriate for most autos and cars drived on open hey ways what's more, city roads. Be that as it may, the ind ustrially accessible segments are not reasonable for military cross country going from desert to ice conditions with bumpy territory The improvement of crossover electric parts for defense purpose is being done in the meantime as innovation development. Thus, the expense for moving a crossover vehicle from exhibition to creation appears to be restrictive particularly when the unwavering quality of cross breed vehicles has not been evaluated legitimately and can't be precisely anticipated.

\section{Potential Solutions}

The challenges of hybrid electric vehicles can be removed by components made up from Silicon-Carbide (SiC), since components made up from Silicon Carbide has higher operating temperature and higher efficiency so removing cooling requirements.

\section{Conclusion}

Crossover electric innovation for military applications offers noteworthy settlements that can't be ignored. The Army recognizes the benefits of cross breed vehicles especially the installed electric power that is a necessity for present and upcoming generations. The handling of full half breed vehicles anyway relies upon the full usage of some basic advancement, for example, silicon Carbide control gadgets, lithium batteries and other high temperature segments. While these empowering advances are being created and developed, In the long run, as silicon carbide and the battery innovations turn out to be increasingly more feasible for military applications, mellow mixture and later full crossover will wind up worthy for handling.

\section{References}

[1] CTC HE-HMMWV Specifications, Mid Atlantic Regional Consortium for Advanced Vehicles, http://www.marcav.ctc.com/projects/hmmwv/hehmm wv_specs.html

[2] Colucci, Frank, Military Vehicles Could Benefit from Hybrid Electric Engines, National Defense Magazine, January 2004 http://www.nationaldefensemagazine.org/issues/2004 /Jan/Milit ary_Vehi cles.htm

[3] Winters, Ken; Hybrid Electric HMMWV; PEI Electronics, Inc. http://www.cte.tv/darpa/HyHMMWV.pdf

[4] Fish, S., Savoie, T., and Vanicek, H. (2001) Modeling Hybrid Electric HMMWV Power System Performance. IEEE Transactions on Magnetics, Vol. 37, No. 1, January 2001, pp. 480-484.

[5] Onoda, S. and Emadi A Conventional, Electric, and Hybrid Electric Vehicles. IEEE Transactions on Vehicular Technology, Vol. 53, No. 2, March 2004, pp. 390-400. 